\title{
Refractive Errors: Prevalence and Pattern among Rural Population of Islamabad, Pakistan
}

\author{
Waseem Akhter ${ }^{1}$, Erum Yousafzai ${ }^{2}$, Afia Matloob Rana ${ }^{3}$, Shakaib Anwar ${ }^{4}$ \\ ${ }^{1}$ Associate Professor, Department of Ophthalmology, Rawal Institute of Health Sciences, Islamabad, Pakistan \\ ${ }^{2}$ Assistant Professor, Department of Ophthalmology, Rawal Institute of Health Sciences, Islamabad, Pakistan \\ ${ }^{3}$ Assistant Professor, Department of Ophthalmology, HBS general Hospital, Islamabad, Pakistan \\ ${ }^{4}$ Professor, Department of Ophthalmology, Rawal Institute of Health Sciences, Islamabad, Pakistan
}

\begin{abstract}
A BST RACT
Background: Refractive error is the most common cause of correctable visual loss worldwide. Decreased vision due to refractive error can be easily corrected with the help of spectacles, contact lenses and refractive surgery. However, there are $42 \%$ of uncorrected refractive errors all over the world. The present study aimed to evaluate different kinds of refractive errors, its prevalence and pattern in patients from rural areas who visited our hospital in the last five years.

Material and Methods: This cross-sectional study enrolled 2,138 patients, who visited eye OPD at Rawal Institute of Health Sciences, Islamabad during a period of five years i.e. from September, 2013 to September, 2018. Patients having only refractive error with an age of five years and above were included in the study. All patients had objective refraction with automated refractometer followed by subjective refraction. Data was entered and analyzed in SPSS version 20.0. Chi-square test was used for comparing groups with a $P$-value of $<0.05$ considered as statistically significant.
\end{abstract}

Results: Compound myopic astigmatism was the most common error found in our study population ( $\mathrm{n}=575 ; 26.9 \%$ ). The second most frequent complaint was simple myopia ( $n=501 ; 23.4 \%)$ followed by presbyopia $(n=441 ; 20.6 \%)$ and mixed astigmatism ( $n=235 ; 11 \%)$. Patients with more than one refractive error included 178 (8.3\%) with mixed astigmatism and presbyopia and 78 (3.6\%) with simple myopia and presbyopia. Compound myopic astigmatism was more prevalent in younger ages compared to older age groups (46.4\% vs $19.9 \%)(P<0.001)$. Mixed astigmatism (12.4\% vs $8.9 \%)$, simple myopia ( $23.8 \%$ vs $22.9 \%)$ and presbyopia $(21.3 \%$ vs $19.5 \%)$ were slightly greater in females than males $(P=0.07)$, respectively.

Conclusions: The prevalence of myopia is significantly higher among female population and young individuals. Mixed astigmatism combined with presbyopia is more common among elderly population.

Key words: Astigmatism, Hypermetropia, Myopia, Presbyopia, Refractive errors

\begin{tabular}{lll}
\hline Authors' Contribution: & Correspondence: & Article info: \\
${ }_{1-3}$ Conception; Literature research; & Waseem Akhter & Received: March 29, 2019 \\
manuscript design and drafting; Critical Email: wsmakhter@yahoo.com & Accepted: May 18, 2020
\end{tabular}

analysis and manuscript review; ${ }^{4}$ Data analysis; Manuscript Editing.

Cite this article. Akhter W, Yousafzai E, Rana AM, Anwar S. Refractive Errors: Prevalence and Pattern among Rural Population of Islamabad, Pakistan. J Islamabad Med Dental Coll.2020; Funding Source: Nil 9(2): 103-108. Doi: 10.35787/jimdc.v9i2.326

Conflict of Interest: Nil

\section{Introduction}

Refractive error is the most common cause of correctable visual loss worldwide and also in
Pakistan. ${ }^{1,2}$ Refractive error is a physiological deviation in which parallel light rays coming from 
infinity do not focus on the retinal plane, when eye accommodation is fully relaxed. ${ }^{3}$ Vision is important for healthy life style while blurred vision leads to injuries, difficulties in driving and depression. ${ }^{4}$ Therefore, "Vision 2020: The Right to Sight" program launched by $\mathrm{WHO}$ and the International Agency for Blindness Prevention (IABP) in 1999 focused on the refractive errors as a priority area to prevent visual impairment that can be corrected. ${ }^{5,6}$ Generally refractive errors are myopia, hypermetropia, astigmatism and presbyopia. In myopia, light rays are focused in front of the retinal plane because of large axial length or abnormally high refractive power of eye. ${ }^{7}$ In hypermetropic type refractive error, light rays are focused behind the retinal plane because of short axial length or abnormally low refractive power of eye. ${ }^{8}$ While in astigmatism, there are more than one refractive foci because of abnormal meridians of refractive surfaces of eye. ${ }^{9,10}$ Decreased vision due to refractive error can be easily corrected with the help of spectacles, contact lenses and surgery. ${ }^{11}$ The refractive correction clinical services are available all over country and worldwide. However, there are $42 \%$ of uncorrected refractive errors all over the world. ${ }^{12}$

This study aims to evaluate different kinds of refractive errors, its prevalence and pattern in patients from rural areas of Islamabad, Pakistan, who visited Rawal Institute of Health Sciences, Islamabad in the last five years.

\section{Material and Methods}

This cross-sectional study comprised of 2,138 patients from rural areas who visited eye OPD at Rawal Institute of Health Sciences, Islamabad during the period of September 2013 to September 2018. Ethical approval was granted by the hospital ethics committee and patients filled a written informed consent at enrolment. Patients five years of age and above with different kinds of refractive errors from rural areas of Islamabad, which are marked by the Islamabad Capital Territory Administration ${ }^{13}$ were included, while patients with any kind of ocular pathology e.g. cataract, keratoconus, ocular trauma and previous eye surgery were excluded. After taking written informed consent, patients were examined using slit lamp, applanation tonometer and 78D fundus lens. All the patients had objective refraction with automated refractometer followed by subjective refraction. Data was collected and entered on a self-structured proforma.

Statistical analysis was performed through SPSS version 20.0. Continuous variable like age was presented as mean and standard deviation. The categorical variables like gender and type of refractive errors were calculated as frequency and percentages, while comparison between the two groups was done using chi-square test. A $P$-value of $<0.05$ was taken as statistically significant.

\section{Results}

A total of 2138 cases were included in this study. Most of the patients ( $n=921 ; 43.1 \%)$ were between 31 and 45 years of age followed by patients aged 45 years or above $(n=453 ; 21.2 \%)$. The mean age of patients was $36 \pm 18.3$ years with a female preponderance ( $n=1294 ; 60.5 \%)$ (Table I).

\begin{tabular}{|l|c|}
\hline \multicolumn{2}{|c|}{$\begin{array}{c}\text { Table I: Frequency distribution of refractive errors } \\
\text { according to age groups and gender ( } \mathbf{n = 2 1 3 8 )}\end{array}$} \\
\hline & No of cases \\
\hline Age groups (years) & $\mathbf{n}(\%)$ \\
\hline Up to 15 & $352(16.5)$ \\
\hline 16 to 30 & $412(19.3)$ \\
\hline 31 to 45 & $921(43.1)$ \\
\hline 45 or above & $453(21.2)$ \\
\hline Mean age \pm SD & $36.0 \pm 18.3$ \\
\hline Gender & \\
\hline Male & $844(39.5)$ \\
\hline Female & $1294(60.5)$ \\
\hline
\end{tabular}


Compound myopic astigmatism was the most common error found in this study ( $n=575 ; 26.9 \%$ ). The second most frequent refractive error was simple myopia $(n=501 ; 23.4 \%)$ followed by presbyopia ( $n=441 ; 20.6 \%)$ and mixed astigmatism $(n=235 ; 11 \%)$. Many patients were found to have more than one refractive error. There were 178 (8.3\%) patients with mixed astigmatism and presbyopia. Another 78 (3.6\%) were found to have simple myopia and presbyopia. about 30 (1.4\%) patients had simple hypermetropia and presbyopia, $27(1.3 \%)$ had hypermetropia and presbyopia and only $6(0.3 \%)$ had compound myopic astigmatism and presbyopia, respectively.

Table II shows distribution and association of refractive errors with gender $(P=0.07)$. Males were more likely to get affected by compound myopic astigmatism (29.3\% vs $25.3 \%$ ). Mixed astigmatism ( $12.4 \%$ vs $8.9 \%)$, simple myopia ( $23.8 \%$ vs $22.9 \%)$ and presbyopia (21.3\% vs $19.5 \%$ ) were slightly greater in females than males respectively (Table II).

When refractive errors were analyzed according to age of patients, it was noted that compound myopic astigmatism was more prevalent in younger ages as compared to older age groups $(46.4 \%$ vs $19.9 \%$ ). Mixed astigmatism (18.1\% vs $6.3 \%$ ) and mixed astigmatism combined with presbyopia (38.9\% vs $0.7 \%)$ were found significantly more common in older ages. Simple myopia was also found significantly greater in younger ages $(43.7 \%$ vs $15.7 \%)$. Overall, the association between different refractive errors and age was statistically significant $(P<0.001)$ (Table III).

\begin{tabular}{|l|c|c|}
\hline \multicolumn{2}{|c|}{ Table II: Association of refractive errors with gender } \\
\hline & $\begin{array}{c}\text { Female (n=1294) } \\
\mathbf{n}(\%)\end{array}$ & $\begin{array}{c}\text { Male (n=844) } \\
\mathbf{n}(\%)\end{array}$ \\
\hline Compound Myopic Astigmatism & $328(25.3)$ & $247(29.3)$ \\
\hline Compound Myopic Astigmatism + Presbyopia & $3(0.2)$ & $3(0.4)$ \\
\hline Hypermetropia + Presbyopia & $17(1.3)$ & $10(1.2)$ \\
\hline Mixed Astigmatism & $160(12.4)$ & $75(8.9)$ \\
\hline Mixed Astigmatism + Presbyopia & $95(7.3)$ & $83(9.8)$ \\
\hline Presbyopia & $276(21.3)$ & $165(19.5)$ \\
\hline Simple Hypermetropia & $37(2.9)$ & $30(3.6)$ \\
\hline Simple Hypermetropia + Presbyopia & $18(1.4)$ & $12(1.4)$ \\
\hline Simple Myopia & $308(23.8)$ & $193(22.9)$ \\
\hline Simple Myopia + Presbyopia & $52(4.0)$ & $26(3.1)$ \\
\hline
\end{tabular}

$* P$-value $<0.05$ was considered statistically significant

\section{Discussion}

Refractive error is the most common correctable cause of decreased vision in developing countries as well as in Pakistan (43\%). ${ }^{14}$ A survey by SignesSoler et al in rural Paraguay also listed refractive errors (58\%) as the major cause of visual impairment followed by retinal problems. ${ }^{15}$ According to World Health Organization bulletin 2010 world load of uncorrected refractive errorsrelated decreased vision (myopia, hypermetropia, astigmatism) is 103 million. ${ }^{14}$ Different factors effecting the prevalence of refractive errors include selected population (urban or rural), developed or developing country, quality of available eye services, tests and conditions used to evaluate the visual acuity, etc. The current study evaluated the prevalence of different type of refractive errors and their association with different age groups and gender. 


\begin{tabular}{|c|c|c|c|c|c|}
\hline \multicolumn{6}{|c|}{ Table III: Association of refractive errors with age } \\
\hline & \multicolumn{4}{|c|}{$\begin{array}{c}\text { Age categories } \\
\mathrm{n}(\%)\end{array}$} & \multirow{2}{*}{$P$-value* } \\
\hline & $\begin{array}{l}\text { Up to } 15 \\
(n=352)\end{array}$ & $\begin{array}{l}16 \text { to } 30 \\
(n=412)\end{array}$ & $\begin{array}{l}31 \text { to } 45 \\
(n=921)\end{array}$ & $\begin{array}{c}45 \text { or above } \\
(n=453)\end{array}$ & \\
\hline Compound Myopic Astigmatism & $113(32.1)$ & $191(46.4)$ & $183(19.9)$ & $88(19.4)$ & \multirow{10}{*}{$<0.001$} \\
\hline Compound Myopic Astigmatism + Presbyopia & $0(0.0)$ & $0(0.0)$ & $2(0.2)$ & $4(0.9)$ & \\
\hline Hypermetropia + Presbyopia & $1(0.3)$ & $1(0.2)$ & $13(1.4)$ & $12(2.6)$ & \\
\hline Mixed Astigmatism & $61(17.3)$ & $26(6.3)$ & $66(7.2)$ & $82(18.1)$ & \\
\hline Mixed Astigmatism + Presbyopia & $2(0.6)$ & $2(0.5)$ & $68(7.4)$ & $106(23.4)$ & \\
\hline Presbyopia & $2(0.6)$ & $3(0.7)$ & $358(38.9)$ & $78(17.2)$ & \\
\hline Simple Hypermetropia & $28(8.0)$ & $8(1.9)$ & $16(1.7)$ & $15(3.3)$ & \\
\hline Simple Hypermetropia + Presbyopia & $0(0.0)$ & $1(0.2)$ & $18(2.0)$ & $11(2.4)$ & \\
\hline Simple Myopia & $145(41.2)$ & $180(43.7)$ & $145(15.7)$ & $31(6.8)$ & \\
\hline Simple Myopia + Presbyopia & $0(0.0)$ & $0(0.0)$ & $52(5.6)$ & $26(5.7)$ & \\
\hline
\end{tabular}

${ }^{*} P$-value $<0.05$ was considered statistically significant

There was a higher trend of myopia especially myopic astigmatism in our study. Shah et al carried out a population survey on refractive errors in Pakistan and reported myopia (36.5\%) as the most common refractive error followed by hypermetropia (27.1\%) and astigmatism (37\%), respectively. ${ }^{16}$ Similarly a Mexican study by GomezSalazar et al. also found myopia as the most common type of refractive error among younger population (10-29 years) and hypermetropia as more common in the older age group. ${ }^{17}$

In our study the different types of myopia as well as hypermetropia were more common in females $(60.5 \%)$ as compared to males (39.5\%). These results are in accordance with a study carried out by You et al. in Beijing, China. ${ }^{18}$ Other studies on prevalence of refractive errors in Bangladeshi adults by Bourne and colleagues, ${ }^{19}$ South Indian adult population by Krishnaiah et al. ${ }^{20}$ and a review by Grzybowski et al. ${ }^{21}$ showed that hypermetropic type of refractive error was more common among females. This is in contrast to our study as hypermetropia was more common among our female population. This difference in results can be attributed to factors affecting prevalence mentioned above, like urban vs rural, developed vs developing country or availability of eye services, etc.

Compound myopic astigmatism was more prevalent in younger ages as compared to older age groups (46.4\% vs $19.9 \%)$. Mixed astigmatism (18.1\% vs $6.3 \%)$ and mixed astigmatism combined with presbyopia ( $38.9 \%$ vs $0.7 \%$ ) were found significantly more common in older ages. Simple Myopia was also found significantly greater in younger ages as compared to older age groups (43.7\% vs $15.7 \%)$. Younger age myopia was also more prevalent $(52.2 \%)$ in a study done by Yingyan et al. ${ }^{22}$

The uneven distribution of trained health services and institution among rural and urban population is a major challenge making it difficult for patients with refractive errors to approach these services. $^{23,24}$ World Health Organization in the global action plan of 2014-2019 for "Universal eye health" also identified provision of resources and development of national policies for prevention of avoidable visual impairment, specifically refractive errors. $^{25}$

The major strength of this study was a large sample size and use of both objective and subjective refraction for testing of visual acuity. The main limitation of the study was that patients with 
refractive errors were enrolled from one institution only; therefore, findings cannot be generalized to the whole rural population of Islamabad.

\section{Conclusion}

The prevalence of myopia and hypermetropia is significantly higher among female population and younger individuals of rural area of Islamabad while mixed astigmatism combined with presbyopic type of refractive error is more common among elderly population.

\section{References}

1. Rensikoff $S$, Pascolini $D$, mariotti SP, Pokharel GP. Global magnitude of visual impairment caused by uncorrected refractive errors in 2004. Bull World Health Organ. 2008; 86(1):63-70. Doi: 10.2471/blt .07 .041210

2. Solange RS, Rafael WC, Adriana B, Luana M, Célia R. Nakanami, et al. Prevalence and causes of visual impairment in low-middle income school children in São Paulo, Brazil. Invest Ophthalmol Vis Sci. 2008; 49(10): 4308-13. Doi: 10.1167/iovs.08-2073

3. Pirro GH, Omar AM, Phillippa C, Robert W, Katie MW, Terri LY, et al. Common mechanisms underlying refractive error identified in functional analysis of gene lists from genome-wide association study results in 2 european british cohorts. JAMA Ophthalmol. 2014; 132(1): 50-6. Doi: 10.1001/ jamaophthalmol.2013.6022

4. John C, Chiu-Fang C, Matthew MZ, Xinzhi Z, Kai MB, Alan RM, et al. The association of health-related quality of life with severity of visual impairment among people aged 40-64 years: findings from the 2006-2010 behavioral risk factor surveillance system. Ophthalmic Epidemiol. 2016; 23(3): 145-53. Doi: 10.3109/09286586.2016.1168851

5. Van CL, Kristen AE. VISION 2020: The right to sight in 7 Years? Med Hypothesis Discov Innov Ophthalmol. 2013; 2(2): 26-9. PMID: 24600638

6. Pizzarello L, Abiose A, Ffytche $T$, Duerksen R, Thulasiraj R, Taylor $\mathrm{H}$, et al. VISION 2020: The right to sight. a global initiative to eliminate avoidable blindness. Arch Ophthalmol. 2004; 122(4): 615-20. Doi: 10.1001/archopht.122.4.615

7. Siegwart JT, Norton TT. Perspective: How might emmetropization and genetic factors produce myopia in normal eyes? Optom Vis Sci. 2011; 88(3): 365-72. Doi: 10.1097/OPX.0b013e31820b053d

8. Rafael I, Hassan $\mathrm{H}$, Mehdi K, Ian GM, Emamian MH, Shariati $M$, et al. Hyperopia and lens power in an adult population: the shahroud eye study. J Ophthalmic Vis Res. 2015; 10(4): 400-07. Doi: 10.4103/2008-322X.158895

9. Flitcroft DI. Emmetropisation and the aetiology of refractive errors. Eye (Lond). 2014; 28(2): 169-79. Doi: 10.1038/eye.2013.276

10. Stambolian D. Genetic susceptibility and mechanisms for refractive error. Clin Genet. 2013; 84(2): 102-8. Doi: 10.1111/cge.12180

11. AK SM, Pourmazar R, Gohary, I. Awareness and attitude toward refractive error correction methods: a population-based study in mashhad. Patient Saf Qual Improv. 2013: 1(1):23-9.

12. Suraj SS, Praveen VN, Sumit $M$, Vasundhara $M$, Bhardwaj A, Vivek G. Prevalence of visual impairment due to uncorrected refractive error: Results from Delhi-Rapid Assessment of Visual Impairment Study. Indian J Ophthalmol. 2016; 64(5): 387-90. Doi: 10.4103/0301-4738.185614

13. Islamabad Capital Territory Administration. Archived 4th April 2011 at the Wayback Machine. Ictadministration.gov.pk. Retrieved on 14 June 2020. http://www.ictadministration.gov.pk/

14. Pascolini D, Mariotti SP. Global estimates of visual impairment: 2010. Br J Ophthalmol. 2012; 96(5): 614-18. Doi: 10.1136/bjophthalmol-2011-300539

15. Signes-Soler I, Hernández-Verdejo JL, Lumeras MA, Verduras ET, Piñero DP. Refractive error study in young subjects: results from a rural area in Paraguay. Int J Ophthalmol. 2017; 10(3): 467-72. Doi: 10.18240/ijo.2017.03.22

16. Shah SP, Jadoon MZ, Dineen B, Bourne RR, Johnson GJ, Gilbert CE, et al. Refractive errors in the adult Pakistani population: the national blindness and visual impairment survey. Ophthalmic Epidemiol. 2008; 15(3): 183-90. Doi: 10.1080/0928658080 2105822 
17. Gomez-Salazar F, Campos-Romero A, GomezCampaña H, Cruz-Zamudio C, Chaidez-Felix M, LeonSicairos N, et al. Refractive errors among children, adolescents and adults attending eye clinics in Mexico. Int J Ophthalmol. 2017; 10(5): 796-802. Doi: 10.18240/ijo.2017.05.23

18. You QS, Wu LJ, Duan JL, Luo YX, Liu LJ, Li X, et al. Prevalence of myopia in school children in greater Beijing: the Beijing Childhood Eye Study. Acta Ophthalmol. 2014; 92(5): 398-406. Doi: 10.1111/ aos.12299

19. Bourne RR, Dineen BP, Ali SM, Huq DM, Johnson GJ. Prevalence of refractive error in Bangladeshi adults: results of the National Blindness and Low Vision Survey of Bangladesh. Ophthalmol. 2004; 111(6): 1150-60. Doi: 10.1016/j.ophtha.2003.09.046

20. Krishnaiah S, Srinivas M, Khanna RC, Rao GN. Prevalence and risk factors for refractive errors in the South Indian adult population: The Andhra Pradesh Eye disease study. Clin Ophthalmol. 2009; 3:17-27. PMID: 19668540
21. Grzybowski A, Kanclerz P, Tsubota K, Lanca C, Saw SM. A review on the epidemiology of myopia in school children worldwide. BMC Ophthalmol. 2020; 20(1): 27. Doi:10.1186/s12886-019-1220-0

22. Ma Y, Qu X, Zhu X, Xu X, Zhu J, Sankaridurg P, et al. Age-specific prevalence of visual impairment and refractive error in children aged 3-10 years in Shanghai, China. IOVS. 2016; 57(14): 6188-96. Doi: 10.1167/iovs.16-20243

23. Gilbert CE, Shah SP, Jadoon MZ, Bourne R, Dineen $B$, Khan MA, et al. Poverty and blindness in Pakistan: results from the Pakistan national blindness and visual impairment survey. BMJ. 2008; 336(7634): 29-32.

24. Wang W, Yan W, Müller A, Keel S, He M. Association of Socioeconomics with Prevalence of Visual Impairment and Blindness. JAMA Ophthalmol. 2017; 135(12): 1295-1302.

25. Gupta N, Kocur I. Chronic eye disease and the WHO Universal Eye Health Global Action Plan 2014-2019. Can J Ophthalmol. 2014; 49: 403-4 